\title{
SABERES DOCENTES MANIFESTADOS SOBRE A PRÁTICA DA EDUCAÇÃO AMBIENTAL (EA): As concepções de duas professoras do ensino fundamental de uma escola pública de Marabá/Pa

\author{
TEACHERS KNOWLEDGE MANIFESTED ON THE PRACTICE OF \\ ENVIRONMENTAL EDUCATION (EE): The conceptions of two \\ elementary school teachers at a public school in Marabá/Pa
}

\author{
Luana Pinheiro Lima ${ }^{1}$ \\ Sandra Cristina Lima Silva ${ }^{2}$ \\ Marcos Guilherme Moura Silva ${ }^{3}$ \\ João Manoel da Silva Malheiro ${ }^{4}$
}

\section{RESUMO}

Entendemos por saberes o conjunto de conhecimentos e experiências adquiridos pelos docentes durante sua trajetória profissional e aplicados em sua prática, constituindo assim sua identidade de educador. A Educação Ambiental caracteriza-se como um conjunto de atividades e práticas ambientais com o objetivo de conscientizar a sociedade e solucionar os problemas do ambiente. Para tanto, esta pesquisa teve como objetivo investigar os saberes docentes necessários à prática da Educação Ambiental (EA) e o desenvolvimento da mesma em uma Escola pública da cidade de Marabá (PA). Realizamos uma pesquisa qualitativa, tendo as informações sido constituídas a partir de entrevistas semi-estruturadas realizadas com duas professoras de Ciências do Ensino Fundamental que desenvolvem em suas aulas trabalhos voltados para a conscientização ambiental de seus alunos. Os resultados apontam que, apesar de alguns saberes serem destacados pelas professoras, faz-se necessário ainda um aprofundamento teórico, cursos de aprimoramento e formação continuada para que os saberes necessários à prática da Educação Ambiental sejam apreendidos, desenvolvidos e constituídos no processo educacional de cada docente, além de destacarmos a relevância de incentivar entre os professores a pesquisa na área.

Palavras-chave: Saberes docentes - Educação Ambiental - Escola.

\begin{abstract}
We understand teachers' knowledge as being the set of knowledge and experience acquired by the teachers during their professional career and applied in practice, thus constituting his identity as an educator. The environmental education has been characterized as a set of environmental activities and practices, which aims at raising awareness in society and solve environmental problems. To that end, this research aimed at investigating the teachers'
\end{abstract}

\footnotetext{
${ }^{1}$ Graduada em Ciências Biológicas/UFPA-MARABÁ

${ }^{2}$ Graduada em Ciências Biológicas / UFPA-MARABÁ

${ }^{3}$ Mestrando do Programa de Pós Graduação em Educação em Ciências e Matemáticas/UFPA

${ }^{4}$ Doutor em Educação em Ciências/UNESP-Bauru
}

AMAZÔNIA - Revista de Educação em Ciências e Matemáticas V.7 - n. 13 - jul. 2010/dez. 2010, V. 7 - n. 14 - jan $2011 /$ dez. 2011 
knowledge base in the practice of Environmental Education (EE) and its development in a public school in the city of Marabá (PA). We conducted a qualitative research, obtaining information from semi-structured interviews conducted with two Elementary Education Science teachers who develop in their classes work geared towards environmental awareness of their students. The results show that although some knowledges are highlighted by the teachers, it remains necessary to provide a deeper theoretical study and courses that promote a continuing education so that the necessary knowledge to implement environmental education can be learned, developed and constituted in the educational process of each instructor, besides highlighting the importance of encouraging research among teachers in this area.

Keywords: Teachers'knowledge - Environmental Education - School

\section{CONSIDERAÇÕES INICIAIS}

É consenso que em um contexto marcado por degradações do meio ambiente, reflexões precisam ser lançadas sobre as práticas sociais, no intuito de se contribuir com novas ações em meio a essa conjuntura.

Vários são os debates acerca dos entraves que residem nas questões ambientais e expressões como "sujeito ecológico" (CARVALHO, 2004), "ecopedagogia" (AVANZI, 2004), “alfabetização ecológica" (MUNHOZ, 2004), "educação ambiental crítica", oponente a uma educação ambiental conservadora (GUIMARÃES, 2004), permitem-nos ter uma ideia da grande difusão teórica lançada sobre o assunto.

Layrargues (2004) faz referências a dois campos distintos (Campo da Educação e Campo Ambiental) que passaram a se complementar e gerar práticas pedagógicas exercidas por um sujeito, antes em anonimato, o educador ambiental. Contudo, apesar dos avanços teóricos envolvendo a educação ambiental, poucos estudos focalizam a escola como lócus de pesquisa e ouvem os saberes dos educadores que podem a vir desencadear reflexões.

A escola, portanto, passa a ser também, um lócus ideal e instrumento de transformação e de sensibilização social, onde "o professor tem a função de mediador na construção de referenciais ambientais e deve saber usá-los como instrumentos para o desenvolvimento de uma prática social centrada no conceito da natureza" (JACOBI, 2003, p.193).

Assim, entendendo a função do professor nas palavras de Jacobi (2003),notamos a ascendência de um ponto em particular: se o professor é mediador na construção de referenciais ambientais, ele produz e constrói saberes, que, por conseguinte, devem ser analisados no intuito de contribuir com os debates teóricos em discussão.

Entre os teóricos ostentados como referenciais para subsidiar essa discussão, Shulman (1987), Tardif (2002) e Gauthier (1998) listam os homens precursores da temática dos saberes docentes, fundamentando os estudos de Pimenta (2005), também tomados como pilares nesteartigo.

Segundo Tardif (2002), é necessário estudar o saber docente relacionando-o com a pessoa e a identidade do professor, com sua experiência de vida, sua história profissional, sua relação com os alunos e com os outros membros da comunidade escolar. Uma das principais estratégias de pesquisa relacionada com essa visão do saber,segundo aquele autor, consiste em "observar atores e/ou falar com eles, fazendo-lhes perguntas sobre suas razões de agir ou de 
discorrer, ou seja, no fundo, sobre os saberes nos quais eles se baseiam para agir ou discorrer" (TARDIF, 2002, p. 200).

Tendo em vista as contribuições propiciadas pelo professor a partir da educação ambiental, sobretudo por sua relação evidente com os alunos, sendo estes corresponsáveis pelo meio em que vivem (JACOBI, 2003), almejamos neste estudo, analisar os saberes docentes presentes na práxis de duas professoras de Ciências do ensino fundamental que ensinam Educação Ambiental em uma escola pública do município de Marabá, localizada no interior do estado do Pará.

Convém ressaltar que o município de Marabá foi um dos quatro municípios brasileiros que participaram do projeto "Global Environment Outlook" (GEO), promovido pelo Programa das Nações Unidas para o Meio Ambiente (PNUMA),que teve como objetivo avaliar o estado do meio ambiente nos níveis global, regional e nacional.

O relatório do projeto GEO, denominado Perspectivas para o meio ambiente urbano: GEO Marabá, traz uma visão panorâmica deste município que se assenta na maior província mineral do mundo, fato este responsável por enormes degradações ambientais cometidas no espaço do município, a partir de projetos de mineração, além de outros agravantes.

Portanto, investigar os saberes de educadoras que convivem com a realidade socioambiental e peculiar deste município,coloca-nos em um patamar de importância ímpar, tendo em vista que estamos retratando sujeitos que em muito podem contribuir com a discussão ora proposta.

\section{PRESSUPOSTOS TEÓRICOS ACERCA DOS SABERES DOCENTES}

Pelo menos nos últimos 30 anos, a questão dos saberes docentes vem sendo discutida de maneira ampla, gerando diversas perspectivas e concepções acerca do professor e seus saberes.Segundo Borges (2001, p.59), publica-se “ um número extraordinário de obras e artigos sobre esse tema, em diversos lugares no mundo todo."

$\mathrm{Na}$ área de Educação Ambiental, Leff (2008) denomina de "Saber Ambiental" o conhecimento a respeito do meio ambiente e diz que este se produz numa relação entre a teoria e a práxis. Entende-se, portanto, que a teoria é o saber, e a prática é o fazer, constituindo assim o saber-fazer do professor, para colocar em prática o desenvolvimento da EA.

Shulman (1987) é um dos autores que mais tem contribuído com a discussão acerca dos saberes docentes (BORGES, 2001; PUENTES et al, 2009). Em seus estudos, ele situou cinco programas de pesquisa sobre o ensino e sobre a docência, dos quais um se destaca por focalizar o professor como sujeito de ações, como ator de decisões, de julgamentos e de atitudes inerentes à sala de aula. Dessa forma, passou-se a observara cognição do professor, que representa, sobretudo, o pensamento dos docentes acerca de suas ações.Com isso, Shulman (1987) sinaliza o início das discussões acerca dos saberes do professor, embora não com essa denominação, o que mais tarde, ganharia força e expandir-seia na América do Norte, em um contexto marcado pela "crise do profissionalismo".

Por sua vez, os estudos de Tardif (2002) e Gauthier (1998) ganham notoriedade por sua abrangência direta na práxis do professor e críticas são lançadas a pesquisadores que elaboram diretrizes a serem exercidas pelo professor, desconsiderando que este é promotor de seus próprios saberes e não utilizador de conhecimentos formalizados por terceiros. 
Gauthier (1998) retrata que embora o ofício de professor remonte a um longo período histórico, pouco se sabe sobre os saberes desse ofício. Na tentativa de compreender um ofício sem saberes e saberes sem ofício, este autor elaborou o que ficou conhecido por "reservatório de saberes", no qual o professor tende a abastecer-se para ensinar.

Tardif (2002) caracteriza esses saberes como [...] plural, compósito, heterogêneo, porque envolve, no próprio exercício do trabalho, conhecimentos e um saber-fazer bastante diversos, provenientes de fontes variadas e, provavelmente, de natureza diferente [...] (TARDIF, 2002, p. 18). Desse modo, o saber não é único, mas diverso e construído, moldado e transformado pelo contexto escolar ao qual o professor está inserido. A tradução e publicação de seus escritos pelo Brasil, influenciaram autores brasileiros e pesquisas foram sendo desenvolvidas na perspectiva de trazer subsídios ao paradigma então emergente. Dentre esses autores, destaca-se Pimenta (2005) afirmando que:

O saber do professor se fundamenta na tríade saberes das áreas específicas, saberes pedagógicos e saberes da experiência. É na mobilização dessa tríade que os professores desenvolvem a capacidade de investigar a própria atividade e, a partir dela, constituírem e transformarem seus saberes-fazeres docentes (grifo nosso).

No que diz respeito ao saberes da experiência, a autora afirma que é a partirda experiência acumulada na vida de cada professor, refletida, submetida a análises, a confrontos com as teorias e práticas, próprias e as de outrem, a avaliações de resultados,que o mesmo vai construindo seu jeito de ser professor.Referente aos saberes das áreas do conhecimento, o professor encontra o referencial teórico, científico, técnico, tecnológico e cultural para garantir que os alunos se apropriem também desse instrumental no seu processo de desenvolvimento humano.Nos saberes pedagógicos, a autora afirma que se encontra o referencial para trabalhar os conhecimentos enquanto processo de ensino, que se dá em situações histórico-sociais, e ensinar em espaços coletivos - as salas de aulas, as escolas, as comunidades escolares, concretamente consideradas.

Gil-Pérez (2001) corrobora com a discussão e compreende os saberes dos professores em três dimensões: Saber analisar criticamente o "ensino tradicional"; Saber preparar atividades capazes de gerar uma aprendizagem efetiva; Saber dirigir trabalho aos alunos e Saber avaliar.

Somamos ainda as contribuições de Freire (1996, p. 22), quando aponta alguns dos saberes fundamentais à prática educativo-crítica, dentre os quais, o pressuposto de que "ensinar não é transferir conhecimento", mas criar as possibilidades para a sua produção ou a sua construção".

Para o autor, ensinar exige aprender, pesquisar, respeito aos saberes dos educandos, curiosidade crítica,ética, rejeição da discriminação, pensar certo, reflexão crítica sobre a prática,identidade cultural, consciência de que somos seres inacabados, respeito à autonomia do educando, bom senso, humildade, tolerância, luta pelos direitos dos educadores,alegria e esperança, convicção de que a mudança é possível, segurança, competência profissional, generosidade, comprometimento, liberdade e autoridade, saber escutar, diálogo e querer bem aos educandos ${ }^{6}$.

Enfatizamos que os saberes defendidos por Gil - Pérez (2001) e Freire (1996) são de necessidade ímpar a serem empregados no cotidiano escolar, tendo em vista que, de modo geral, a metodologia educacional empregada e o contrato didático fincado residem num

\footnotetext{
${ }^{5}$ Grifo do autor

${ }^{6}$ Grifo nosso 
tradicionalismo pedagógico, no qual de maneira geral, o aluno assume uma postura passiva e o professor torna-se o único referencial e promotor do conhecimento.

\section{A EDUCAÇÃO AMBIENTAL EM FOCO}

Várias são as conceituações teóricas que abrangem o termo educação ambiental, com o qual Dias (2003) corrobora afirmando se tratar de um processo permanente no qual os indivíduos e a comunidade tomam consciência do seu meio ambiente e adquirem conhecimentos, valores, habilidades, experiências e determinação que os tornem aptos a agir e resolver problemas ambientais presentes e futuros.

Segundo Pereira (1993), EA é a adaptação contínua do homem ao ambiente onde ele vive e ao seu nicho ecológico. Compreende que os objetivos principais da EA sejam proporcionar um conjunto de situações de experiências que possibilitem colocar as pessoas em contato direto com o mundo onde vivem; sensibilizar as pessoas para a importância do ecossistema que nos envolve; discutir a importância do ambiente para a saúde e o bem estar do indivíduo;desenvolver no educando o sentido ético-social diante dos problemas ambientais;orientar as pessoas para as relações entre o ambiente em que vivemos e o exercício da cidadania e comparar o chamado desenvolvimento econômico com a degradação ambiental e a qualidade de vida.No entanto, acreditamos que, para atingir seus objetivos, a EA precisa estar inserida no currículo escolar, não como uma disciplina, mas contextualizada em todas as disciplinas de forma interdisciplinar e como um tema transversal.

Em Dias (1992), encontramos um conceito voltado para o ensino, enfatizando a interdisciplinaridade e a participação da comunidade. Segundo ele, a EA é "um conjunto de conteúdos e práticas ambientais, orientadas para a resolução dos problemas concretos do ambiente, através do enfoque interdisciplinar e de uma participação ativa e responsável de cada indivíduo da comunidade".

Para a inserção da EA no currículo escolar, especificamente no ensino fundamental, os PCN (BRASIL, 1997) trazem a proposta de uma abordagem ambiental integrada entre as disciplinas e a sociedade de forma transversal e interdisciplinar, tratando das questões ambientais relevantes. Sendo um tema transversal, a EA deve perpassar por todas as disciplinas, não se caracterizando por uma disciplina específica, mas priorizando a interdisciplinaridade, criando, assim, uma nova prática e modelo de abordagem.

De acordo com Brasil (1999, p.1),

Art. 1ํㅡㄹ Entendem-se por Educação Ambiental os processos por meio dos quais o indivíduo e a coletividade constroem valores sociais, conhecimentos, habilidades, atitudes e competências voltadas para a conservação do meio ambiente, bem de uso comum do povo, essencial à sadia qualidade de vida e sua sustentabilidade.

Nestes termos, podemos dizer que a EA é um processo contínuo e demorado e tem como objetivo principal fazer com que os indivíduos se conscientizem a respeito da importância da conservação do ambiente em que vivem, tornando-os participativos na defesa e recuperação do mesmo.

Ainda de acordo com Brasil (1999), todos têm direito a EA, incumbindo ao poder público, às instituições educativas, aos órgãos do Sistema Nacional de Meio Ambiente (SISNAMA), aos meios de comunicação, às empresas e à sociedade, definir políticas públicas que a promovam, seja a partir de ações, programas educacionais, disseminação de informações e colaboração de todos para a prevenção, identificação e solução dos problemas 
ambientais. No entanto, o que constatamos através de observações sistemáticas é que pouco se tem feito para o cumprimento integral da lei em questão.

\section{CARACTERIZANDO OS PROCEDIMENTOS METODOLÓGICOS}

A escola lócus desta pesquisa é pública, situa-se na cidade de Marabá, sudeste do estado do Pará,e se destaca nos números consideráveis de alunos aprovados nos vestibulares, no crescente índice do $\operatorname{IDEB}^{7}$ nos últimos anos, no incentivo à prática esportiva como fonte alternativa de vida saudável em contraposição à vida do crime e das drogas,na inclusão digital,que oferece curso de informática básica tanto aos alunos, quanto à comunidade de um modo geral.

Os sujeitos da pesquisa consistiram em duas professoras de Ciências do $6^{\circ}$ e $7^{\circ}$ ano do Ensino Fundamental, as quais estão identificadas por "P1" e "P2". Dentre os critérios de escolha dos referidos sujeitos, prezamos por professores que desenvolvem em suas práticas trabalhos diferenciados de sensibilização ambiental. Nessa perspectiva, nossa escolha incidiu nas duas professoras em questão, que realizam atividades relacionadas à EA na escola, tais como seus envolvimentos com plantio de horta e da reciclagem ou reutilização de materiais como garrafa pet e papel.

A abordagem caracteriza-se como qualitativa, tendo em vista que os procedimentos adotados nessa pesquisa correspondem aos cinco pressupostos preconizados por Bogdan e Biklen, (1994), os quais afirmam que a fonte direta dos dados é o ambiente natural, que o investigador constitui o instrumento principal, que os dados são predominantemente descritivos É dado um valor mais preciso ao processo do que aos resultados ou produtos; a análise dos dados é tendenciosa, a indução e o significado são de importância vital.

Entrevistamos as docentes no seu próprio local de trabalho para termos um contato direto com as mesmas. Cada uma, em seu momento particular, foi receptiva à nossa presença e, depois de uma conversa geral a respeito da EA, realizamos a entrevista individual com questões abertas, as quais dissertavam sobre os saberes docentes manifestados na prática da EA,o papel que a escola desempenha para o desenvolvimento da EA, os temas relacionados ao meio ambiente discutidos em sala de aula, bem como se a transversalidade e interdisciplinaridade estavam acontecendo.

Utilizamos como recurso para a constituição das informações a videogravação, com a qual pudemos capturar a reação, opinião e reflexão das entrevistadas diante das questões. As informações capturadas em vídeo foram vistas e ouvidas repetidas vezes e as falas transcritas rigorosamente, o que nos possibilitou analisar com clareza o material, discutindo acerca das frases importantes e necessárias para o esclarecimento do problema de pesquisa.

\section{DANDO VOZES AOS SUJEITOS EM QUESTÃO: UMA ÊNFASE SOBRE OS SABERES ENCONTRADOS E SOBRE A EDUCAÇÃO AMBIENTAL NA ESCOLA}

Após a estruturação metodológica e a constituição e análise das informações, sistematizamos os dados em duas categorias de análise, assim compreendidas: i) Os saberes sob a perspectiva dos sujeitos; ii) Educação Ambiental na escola: um olhar reflexivo-crítico.

\footnotetext{
${ }^{7}$ Índice de Desenvolvimento da Educação Básica, criadopelo MEC em 2007 para medir a qualidade de cada escola e de cada rede de ensino.
} 


\section{OS SABERES SOB A PERSPECTIVA DOS SUJEITOS}

Nesta categoria, discorremos a respeito dos saberes que as professoras entrevistadas julgaram necessários para ensinar EA. Elas destacaram a importância de um conhecimento prático oriundo do dia a dia e construído a partir de diversas fontes. De acordo com P1, [...] os saberes que conhecemos são aqueles que vivemos... o que fazemos no dia a dia e o que vemos, seja na televisão, em sites, em revistas, em jornais e na internet [...].

Percebe-se que a práxis da professora em questão está imbricada pelo contexto onde está inserida. Muitos dos saberes mobilizados em sala de aula pelo professor advêm de suas experiências de vida, propiciando um saber experiencial (TARDIF, 2002; GAUTHIER, 1998; PIMENTA (2005); FIORENTINI et. al., 1999).

Gauthier (1998) conceitua o saber experiencial como um saber privado: o professor através do tempo cria uma jurisprudência, constituindo estratégias e concepções concernentes ao ensino, de modo a acreditar nelas. Nessa perspectiva, Tardif (2002) afirma que os saberes oriundos da experiência de trabalho cotidiana parecem constituir o alicerce da prática e da competência profissionais, e complementa que os saberes aprendidos na prática cotidiana, nela mesma são empregados, e servem para resolver os problemas dos professores em exercício.

Porlán Ariza et al. apud Cunha (2011) vem complementar afirmando que os saberes da experiência se referem aos saberes produzidos pelos professores no exercício da docência; brotam da experiência e são por ela validados; podem se manifestar como crenças explícitas, imagens, metáforas e princípios de atuação.

Ainda de acordo com P1,

[...] existe o saber da conscientização de cada pessoa e saber o que deve ser feito por isso (meio ambiente) [...] ter uma consciência melhor sobre o que fazer com o lixo... a se conscientizar desde cedo...

Percebe-se que a professora P1 acredita que todos somos detentores de um saber autoconsciente sobre o meio ambiente, aqui denominado de saber da conscientização ambiental, de modo que o desenvolvimento do mesmo tende a desenvolver uma consciência de sustentabilidade para com o meio ambiente.

Segundo Jacobi (2003, p.196), “a educação ambiental aponta para propostas pedagógicas centradas na conscientização, mudança de comportamento, desenvolvimento de competências, capacidade de avaliação e participação dos educandos". Nesse sentido, a escola, a partir de seus professores, passa a ser uma grande aliada e construtora de uma consciência ambiental crítica e sustentável.

Contudo, Guimarães (2004) assinala que mesmo com os números consideráveis de ações que objetivaram uma conscientização massificada na sociedade, pouco se reduziu nos índices de degradações ambientais.

Este problema citado por Guimarães (op. cit.) se deve ao fato de que se tempriorizado somente a conscientização, esquecendo-se que a abordagem em EA é um passo-a-passo que, de acordo com Dias B. C. (2011), consiste na sensibilização de todos os envolvidos na realidade socioambiental, na informação para que cidadãos bem informados tenham condições de questionar e pressionaras autoridades; na mobilização que visa a orientar os 
grupos envolvidos a cooperarem na transformação dos problemas socioambientais, e,no passo final, que é a ação,em que os grupos envolvidos, uma vez sensibilizados, informados e mobilizados partem para uma ação mais direta em relação ao problema, geralmente realizando um projeto de intervenção.

Segundo a professora P2, primeiramente o profissional tem que saber sobre as questões ambientais, sobre os acontecimentos e fatos que estão acontecendo no mundo, ficar informado e atualizado acerca do meio ambiente no qual está inserido.

\begin{abstract}
Antes de tudo, o profissional da área tem que estar com bastante interação sobre as questões ambientais, sobre a preservação [...]como se pode usar o meio ambiente tirando um meio de vida mais sustentável [..] a questão do lixo, a questão da higiene ambiental, a questão do som[...] Atualmente, o profissional tem que estar bem inteirado de todas essas situações.
\end{abstract}

A professora P2 ainda complementa afirmando que "saber ensinar educação ambiental engloba um enfoque humanista, ser democrático com o pluralismo de ideias, ter reconhecimento e respeito a culturas".

A comunidade escolar caracteriza-se por sua diversidade.. Por ser plural e heterogênea, a EArequer educadores que em suas aulas tenham a ótica de um aprendiz em sua totalidade, propenso a erros e acertos, de modo que professor e aluno sejam co-responsáveis pela aprendizagem (FREIRE, 1996). Educadores democráticos mantêm um relacionamento de respeito aos diferentes pontos de vista, opiniões, ideologias e pensamentos, sem desmerecer ou enfatizar a cultura de um ou outro. Esta é uma obrigatoriedade ética como enfatiza Freire (1996, p. 59).

Contudo, se forem levadas a cabo as discussões emergentes sobre a educação ambiental contemporânea, especificamente o movimento denominado ecopegagogia (GADOTTI, 2000), notar-se-á que este saber se mostra controverso, tendo em vista que nas fundamentações da ecopedagogia, norteia-se uma mudança de pensamentos, uma crítica à cultura capitalista e dominante, na qual o consumo e o pensamento sustentável caminham em descompassos e em desacordos. Assim, nas palavras de Ruscheinsky (2004, p.60), "um saneamento basilar deve ocorrer inclusive nas mentes, nos comportamentos, nos significados, no imaginário, nos referenciais culturais."

\title{
EDUCAÇÃO AMBIENTAL NA ESCOLA: UM OLHAR REFLEXIVO CRÍTICO
}

Nesta categoria, apresentamos a opinião das educadoras a respeito de suas perspectivas sobre a EA na escola, suas óticas sobre a transversalidade e interdisciplinaridade, reflexões sobre suas próprias práticas e os entraves encontrados no âmbito escolar. Vejamos:

A escola deve trabalhar em primeiro lugar com os conhecimentos ambientais, tendo em vista que desde cedo devemos ensinar uma pessoa a ter uma consciência ambiental [...] Tem que se conscientizar desde cedo porque é bem mais fácil mudar o conhecimento de uma criança, do que mudar a de um adulto que esta com o conhecimento formado... (P1).

A EA na escola deve ajudar os alunos e professores a construírem valores sociais, conhecimentos, habilidades, atitudes e competências voltadas para a preservação do meio ambiente... (P2). 
Percebemos nas falas das duas professoras em questão que o saber da conscientização ambiental, anteriormente debatido, tem que fazer parte do cotidiano do aluno, desde sua base escolar, tendo em vista que se tornará bem mais complexo moldar uma consciência sustentável, quando este sujeito acomodar-se em suas práticas não sustentáveis.

De acordo com Brasil (1999), a EA é entendida como um processo por meio do qual o indivíduo e a coletividade constroem valores sociais, conhecimentos, habilidades, atitudes e competências voltadas para a conservação do meio ambiente. Está sob a incumbência das instituições educativas promover a EA de forma integrada em todos os níveis e modalidades do processo educativo.

Dessa forma, a formação de um sujeito ecológico (CARVALHO, 2004) tem na escola um de seus pilares, na medida em que cada educador desenvolva e contribua com uma educação ambiental crítica (GUIMARÃES, 2004), substanciada em valores, conhecimentos, habilidades e atitudes voltadas ao meio ambiente, como bem destacou a professora $\mathrm{P} 2$.

As docentes apontam, ainda, que a EA promovida na escola investigada não vem sendo trabalhada de maneira transversal e interdisciplinar, conforme relatam:

Interdisciplinaridade entre a EA, a matéria e os professores não estão sendo executadas em sala de aula porque a preocupação maior acontece quando há conferências de meio ambiente e feira de ciências, por exemplo... o que representa um déficit que a escola tem atualmente (P1).

[...] precisamos ainda de muita capacitação, de recursos humanos para um melhor desenvolvimento de projetos e de pesquisas, bem como se definir melhores metodologias e instrumentos para se trabalhar (P2).

O reconhecimento de suas limitações, os poucos momentos interdisciplinares promovidos pela escola e a necessidade de cursos de formação continuada externalizada nas falas das docentes retratam um contexto onde ainda há muito a se fazer. Gonçalves e Gonçalves (1998, p.108) afirmam que quando o professor busca por uma formação continuada "é porque sente necessidades, desejos, inquietações, ansiedades", circunstâncias estas que não podem ser desconsideradas.

Percebemos, ainda, a vontade explícita de se trabalhar com projetos e com pesquisa, mesmo com os obstáculos listados por P2 na escola onde leciona. Esse fato torna-se preponderante de ser enfatizado, tendo em vista que o saber da pesquisa como complemento da prática pedagógica pode ser um fator importante na construção de práticas ambientais mais sustentáveis. Como enfatiza Freire (1996, p. 77 e 79), "constatando, nos tornamos capazes de intervir na realidade, tarefa incomparavelmente mais complexa e geradora de novos saberes do que simplesmente a de nos adaptar a ela".

Referente às reflexões inerentes a sua ação prática, a docente P2 avalia-se de modo positivo, pois os alunos trabalham em conjunto e levam para casa o que aprenderam. Conforme afirmado,

Trabalhamos bastante com reciclagem e com reaproveitamento, com horta,com papéis e garrafa pet. Estamos tentando que eles tenham uma vida mais saudável trabalhando com a horta e trocando os alimentos industrializados por alimentos mais saudáveis. E no caso da reciclagem, mostramos para eles que lixonão 
exatamente é lixo, mas se torna matéria-prima e pode tornar-se uma coisa bacana e bonita (P1).

Trabalhar a EA com crianças e adolescentes é uma tarefa árdua, porém, geradora de muitos frutos quando conta com a participação ativa do aluno no processo de aprendizagem. A professora não somente explica os benefícios da horta orgânica e da reciclagem e reutilização, mas põe em prática a teoria, e os próprios alunos aprendem a plantar e cuidar da horta e fabricam objetos de materiais reciclados.

Nessa circunstância, o professor assume papel fundamental e de importância ímpar para a mudança da consciência ambiental dos discentes, pois, "enquanto ator social, o professor desempenha o papel de agente de mudanças, ao mesmo tempo em que é portador de valores emancipadores em relação às diversas lógicas que estruturam tanto o espaço social quanto o espaço escolar" (TARDIF, 2002, p.303).

A docente (P2) enfatiza que a sua ação prática tem poucos resultados, muito embora já tenha avançado, bem como reflete sobre a falta de capacitação e formações continuadas:

\footnotetext{
Os resultados são sucintos [...] precisa-se avançar mais, por exemplo, nas ações educacionais voltadas à sensibilização da coletividade sobre questões ambientais e sua organização, à participação na defesa da qualidade do meio ambiente, apesar de já ter avançado bastante. Precisa-se de professores mais capacitados, formações continuadas para obtermos resultados mais satisfatórios. É necessária uma aplicabilidade melhor dessas aulas sobre as questões ambientais do nosso planeta (P2).
}

Para Pereira (1993) apud Oaigenet al.(2000) a EA vem encontrando uma série de obstáculos e dificuldades, tais como: a falta de recursos humanos qualificados para tal fim; o isolamento da escola; a pouca participação da comunidade nas decisões; o planejamento escolar desvinculado da realidade local; os sistemas de avaliação rígidos e sem criatividade; a rigidez da estrutura escolar e a falta de recursos.

\section{REFLEXÕES FINAIS}

Conforme foi exposto, poucos pesquisadores que argumentam sobre a educação ambiental focalizam seus estudos nos saberes dos educadores ambientais e de suas reflexões. Esta investigação centrou-se no saber do professor, por entender ser este um sujeito com aspectos cognitivos que podem subsidiar reflexões importantes acerca das questões ambientais contemporâneas.

Com efeito, os saberes docentes das depoentes empregados na EA são os advindos de suas experiências de vida, da prática cotidiana e do que vêem em mídias impressas ou televisivas, sendo estas as principais fontes de informação e conhecimento. Nesse sentido, Tardif (2002, p. 17) afirma que "[...] embora os professores utilizem diferentes saberes, essa utilização se dá em função do seu trabalho e das situações, condicionamentos e recursos ligados a esse trabalho" (TARDIF, 2002, p. 17); 
Percebeu-se que a escola tem grande parcela de importância e responsabilidade na promoção da EA, principalmente com as crianças que estão ainda em processo de desenvolvimento mental, contudo, explicitou-se a necessidade de apoio e investimento sobre projetos e pesquisa, o que desencadearia contribuições importantes para a construção de valores e atitudes ambientais tanto em professores, quanto nos alunos.

Um olhar preciso deve ser lançado sobre a falta de cursos de aperfeiçoamento profissional entre os professores que ensinam educação ambiental no município de Marabá, tendo em vista o próprio reconhecimento deste agravante por parte das professoras, bem como nos investimentos em material didático, metodológicos, projetos e pesquisas.

Em suma, os saberes manifestados pelas docentes entrevistadas consistem em um saber que emerge da experiência e da realidade, um saber de conscientização ambiental, o saber advindo da pesquisa, bem como o saber da cultura sustentável sobre a cultura capitalista,

Somos conscientes de que os saberes aqui elencados estão longe de serem todos os necessários à prática da EA. Ass entrevistadas no decorrer do tempo, na caminhada, em suas trajetórias, constituirão e descobrirão ainda muitos outros saberes, pois, "o tempo surge como um fator importante para compreender os saberes dos trabalhadores, uma vez que trabalhar remete a aprender a trabalhar, ou seja, a dominar progressivamente os saberes necessários à realização do trabalho" (TARDIF, 2002, p.57).

O professor desempenha o papel de agente de mudanças (TARDIF, 2002, p.303),mesmo sendo minoria e enfrentando muitas dificuldades, "é a partir deste saber fundamental: mudar é difícil, mas é possível, que vamos programar nossa ação políticopedagógica" (FREIRE,1996, p. 79). Afinal, a educação é progressista, crítica, formadora e“uma forma de intervenção no mundo" (idem, p. 98).

\section{REFERÊNCIAS}

AVANZI, M. R.Ecopedagogia. In: Identidades da Educação Ambiental brasileira. Philippe Pomier Layrargues (coord.). Ministério do Meio Ambiente. Diretoria de Educação Ambiental. Brasília, 2004

BOGDAN, R.; BIKLEN, S. Investigação qualitativa em educação. Porto: Porto Editora, 1994.

BORGES, C. Saberes docentes: diferentes tipologias e Classificações de um campo de pesquisa. Educação \& Sociedade, ano XXII, nº 74, Abril, 2001

BRASIL, Secretaria de Educação Fundamental. Parâmetros Curriculares Nacionais: Meio ambiente e saúde. Brasília, MEC/ SEEF, 1997.

, Lei $\mathrm{n}^{\circ}$ 9795, de 27 de abril de 1999. Política Nacional de Educação Ambiental. Diário Oficial, Imprensa Nacional, 1999.

CARVALHO, M. P. Sentidos do saber e do fazer docente em Educação Ambiental: um estudo sobre as concepções dos professores. Anápolis: Centro Universitário, 2009. 
CARVALHO, I.C.M. Educação Ambiental Crítica: nomes e endereçamentos da educação. In: Identidades da Educação Ambiental brasileira. Philippe Pomier Layrargues (coord.). Ministério do Meio Ambiente. Diretoria de Educação Ambiental. Brasília, 2004

CUNHA, E. R. Os saberes docentes ou saberes dos professores. Disponível em http://www.nead.unama.br/prof/producao.asp?IDProf=102.Acesso em: 31 ago. 2011.

DIAS, B. C. 2011. Os diferentes niveis de abordagem em Educação Ambiental. In: Blog Educação Ambiental Crítica [online]. Disponível em http://eacritica.wordpress.com/2011/05/16/osdiferentes-niveis-de-abordagem-em-educacao-ambiental/ Acesso em: 22 dez 2011.

FREIRE, P. Pedagogia da autonomia: saberes necessários à prática educativa. São Paulo: Paz e Terra, 1996 (Coleção Leitura).

FIORENTINI, D; NACARATO, A. M.; PINTO, R. A. Saberes da experiência docente em Matemática e educação continuada. Quadrante: Revista teórica e de investigação. V.8. Revista semestral da associação de professores de Matemática de Portugal. Lisboa, Portugal,1999.

GADOTTI, M, Pedagogia da Terra. São Paulo: Fundação Peirópolis, 2000

GAUTHIER, C. Por uma Teoria da Pedagogia: pesquisas contemporâneas sobre o saber docente. Ijuí (RS): Unijuí, 1998.

GONÇALVES, T. V. e GONÇALVES, T.O. Reflexões sobre uma prática docente situada: buscando novas perspectivas para a formação de professores. In Cartografia do trabalho docente (Org.) Corinta M. G. Geraldi; Dario Fiorentini e Elisabeth Pereira - Mercado das Letras: Campinas, SP,1998.

GUIMARÃES,M. Educação Ambiental Crítica. In: Identidades da Educação Ambiental brasileira. Philippe Pomier Layrargues (coord.). Ministério do Meio Ambiente. Diretoria de Educação Ambiental. Brasília, 2004

JACOBI, P. Educação ambiental, cidadania e sustentabilidade. Cadernos de Pesquisa, n. 118, março, 2003

LAYRARGUES, P.P.Apresentação: (Re) Conhecendo a educação ambiental brasileira.In: Identidades da Educação Ambiental brasileira. Philippe Pomier Layrargues (coord.). Ministério do Meio Ambiente. Diretoria de Educação Ambiental. Brasília, 2004

LEFF, E. Saber ambiental. 6. ed. Petrópolis: Vozes, 2008.

MALHEIRO, J. M. S. 2011. Organização e Orientação do TAC (Trabalho Acadêmico de Conclusão). 117 p. Instituto Federal de Educação, Ciência e Tecnologia do Pará. Pará. 2011 
MUNHOZ, D. Alfabetização ecológica: de indivíduos às empresas do século XXI. In: Identidades da Educação Ambiental brasileira. Philippe Pomier Layrargues (coord.). Ministério do Meio Ambiente. Diretoria de Educação Ambiental. Brasília, 2004

OAIGEN, E. R. et al. Educação, Ambiente e Educação Ambiental: As concepções históricas e epistemológicas da sociedade atual. Canoas (RS): Universidade Luterana do Brasil, 2000

PIMENTA, S. G. Formação de Professores: identidade e saberes da docência. IN: PIMENTA,S. G. (Org.) Saberes pedagógicos e atividade docente. São Paulo (SP): Cortez, 2005.

PUENTES, R. V. AQUINO, O. F.; NETO, A. Q. Profissionalização dos professores: Conhecimentos, saberes e competências necessários à docência. Educar. Curitiba (PR). N.34, p. 169-184, 2009. Editora UFPR.

PRESTES, M. L. M. A Pesquisa e a construção do conhecimento cientifico: do planejamento aos textos, da escola à academia. 3ed. São Paulo: Rêspel, 2008.

RUSCHEINSKY, A. Atores Sociais e Meio Ambiente. In: Identidades da Educação Ambiental brasileira. Philippe Pomier Layrargues (coord.). Ministério do Meio Ambiente. Diretoria de Educação Ambiental. Brasília, 2004

TARDIF, M. Saberes Docentes e Formação Profissional. Petrópolis (RJ): Vozes, 2002.

SHULMAN, L. Knowledge and teaching: Foundations of the new reform. Harvard Educational Review, $\mathrm{n}^{\circ}$ 1, vol. 57, febr.1987, p. 1-22. 